\title{
LESSON EFFECTIVENESS, STRONG AND WEAK SIDES OF THE INITIAL IMPLEMENTATION OF THE INTEGRATED LANGUAGE APPROACH
}

We analyse effectiveness of the French lesson in the initial implementation of the method called integrated language approach at primary school. The article presents the results of the qualitative research methods - indirect observation, interaction analysis and collective observation and content analysis. We summarise also strong and weak sides of the implementation of the method.

Keywords: Integrated language approach, FREPA, French, English, effectiveness.

\section{Introduction}

In this paper, we deal with teaching French by the aid of English. In the European Centre for Modern Languages in Graz (Institution of the Council of Europe), teaching second language with the aid of the first foreign language is generally called language integrated approach (see FREPA - Framework of reference for Pluralistic Approaches). In 2012, we tried to implement language integrated approach within the selected schools in Nitra's region. To conclude, we proceeded by means of indirect observation (video records and records' protocol), interaction analysis, collective observation and feedback.

\section{General background about pluralistic approaches}

Pluralistic approaches to teaching languages and cultures are new didactic trends in language policy. The general aim for learner [1] is to cognitively link all knowledge from languages and cultures he/she learned or acquired, to use it in order to construct and enrich self plurilingual and pluricultural competence and thus to communicate [2], [3] and [4], to live and to socialise in multicultural and multilingual Europe. Within the learning process, learners are to develop their plurilingual and pluricultural knowledge, skills and attitudes through four pluralistic approaches.

Early acquisition of modern languages develops metacognitive functions. It positively influences mother tongue and mastery of other school subjects. Pluralistic approaches [5] interconnect school subjects and thus create and strengthen cross-curricular teaching. When applying the integrated language learning (approach), we teach, e.g., French language through Slovak and English. This approach aims to develop, compare, analyse, synthesise knowledge and cognitive processes involved in the learning of second foreign language through the first foreign or native language. Inter-comprehension between related languages which is the second pluralistic approach confronts multiple language understanding (languages from the same linguistic branch) on different levels and in different areas. It initiates understanding of languages and can be carried out through contrastive analysis, a sort of systematisation of similar lexical units (dialexemes), similar mechanisms in syntax, spelling, pronunciation or through related or identical etymological bases. Awaking to languages approach activates learner's interest for a variety of languages and cultures. Desire and curiosity of small learners to see or to learn foreign languages the school does not tend to offer in curriculum is considered as sort of pluricultural and plurilingual warm up. Since the cultural adaptation competence is a part of language learning, language communication and everyday socialisation tasks, the intercultural approach which is present in all approaches and mingle with them, aims to create a positive and anti-prejudiced attitudes to people who we do not know. Intercultural approach includes techniques and principles of multicultural education, ethical education, history, geography and others.

\footnotetext{
* Jana Birova

Department of Translation Studies, Faculty of Arts, Constantine the Philosopher University Nitra, Slovakia

E-mail: jbirova@ukf.sk
} 


\section{Integrated language approach}

Approaches developing plurilingual competence are based on the results of the examination of contrastive and comparative linguistics [6] and [7]. Contrastive linguistics is the scientific discipline that deals with synchronous comparing of linguistic systems. Based [8] (p. 113) on linguistic structuralism, its aim is to compare languages from a linguistic point of view. Other equally important linguistic starting-points for foreign language teaching are comparative and cognitive linguistics, inspired by Chomsky and his conviction of the need to study languages by deduction from the human mind [8]. The subject of comparative linguistics is the application of research results [9] (p. 33) which concern two or more compared languages but not for the purpose of linguistics, but for the teaching foreign language objectives. Experts examine [9] (pp. 144-116) mutual influences of foreign languages and influence of the mother tongue. Each of the learners meets other procedures and strategies. Explicit comparisons [10], interferences and transfers are made on phonological, grammatical, lexical and etymological level. The techniques comparing sociolinguistic and pragmatic aspects such as language functions or speech acts in situational contexts focus on some points from cognitive linguistics. When comparing, teachers primarily centre upon positive transfer from one language to another, but also upon negative interference. Learning process of pronunciation or grammar is often manifested by positive transfers from a foreign language. When learning vocabulary, positive transfer of the first foreign language is often overlapped with interference effects of the mother tongue [10].

Debyser [9] assumes that researchers in the field of comparative linguistics will deal with other problem areas in foreign language learning and other problems in mother tongue acquisition - hence the need of psycholinguistic studies, the need of theory of interference studies as well as deeper comparative reviews.

\section{Techniques and principles of integrated language approach}

The following concepts are the theoretical basis for the application of pluralistic approaches to teaching languages and cultures.

\begin{tabular}{|l|c|}
\hline Concepts & \multirow{2}{*}{$\begin{array}{c}\text { Education of } \\
\text { tolerance with } \\
\text { Tespect to otherness }\end{array}$} \\
\hline Valerance & \\
\hline Representations, imaginations & \\
\hline Worldview & \\
\hline Attitudes, prejudices, stereotypes & Sociocultural and \\
Awareness of oneself & cociolinguistic \\
Myself and others, ethnocentrism
\end{tabular}

\section{FREPA descriptors as means to evaluate pluralistic subcompetences}

The framework FREPA, issued by the European Council [11], represents main ideas for creating pluralistic activities developing linguistic and cultural awareness, metacognition as well as plurilingual and pluricultural competence. Since the framework should have the role of application, the creative team of the European Centre for Modern Languages in Graz (institution of the Council of Europe) has also created a bank of activities. Tasks are available on the project website http://carap. ecml.at. Activities are accompanied by descriptors that indicate the developed knowledge, skills and attitudes [12].

FREPA is to lead language teachers to the creation of new activities for the further context of multi or plurilingualism. 


\section{Research procedure}

\subsection{Research questions and methodology}

This paper integrates both qualitative and quantitative research. We focus on determining the how as well as the what, where, and when of our research topic. The study poses these research questions. How did learners succeed in performing in a variety of languages? What content and how much did they perform? Under what conditions did they perform? What advantages and disadvantages does the approach bring into foreign language teaching? In order to determine answers to these questions, we must have created a lesson plan respecting principles of language integrated approach. The method of indirect observation (video record) of the lesson was realised after.

To do a deep interaction analysis of teacher's talk and students' talk and performances, to see task comprehension as well as language content appropriateness, construction of record protocol was needed. The interaction analysis is in its principle a quantitative research method. It's easy to measure minutes of teacher's or learners' talk and in this regard we answer the question how much and what learners performed.

To make crucial points on effectiveness of the first implementation, we needed to realise a collective experts' observation of the video record. Methodology experts as well as experts in teaching process and language policy met in order to evaluate strong and weak sides of the first implementation.

Content analysis was the last research method by which we summarised (analysed) the FREPA descriptors [11] within the activity design and objectives.

\subsection{Research starting points and research sample}

The research was carried out in primary school Kniezata Pribinu, Nitra on $5^{\text {th }}$ June 2012 in the class of 514 years-old learners (a group of 8.A class) whose mother tongue is Slovak, first foreign language is English (6-years study) and second foreign language is French (2-years study). As the integrated language approach can be applied mainly during presentation and practice stages of learning process with the final impact on metacognition and on achieving plurilingual and pluricultural communicative competence, our research was held within these stages, too.

Pluralistic approaches are new trends in language policy and teachers of French are not aware explicitly of their principles and techniques. For the initial implementation, we opted for teaching trainees who attend methodology of teaching French classes. They became our multiplier approach agents.

As for the content analysis, this was held after class videorecord. FREPA document defines a list of classified descriptors which are to evaluate the development of pluralistic competences within the designed activity. Evaluation of activity by means of descriptors was the main objective of the mentioned content analysis.

\section{Discussion}

Qualitative research consisted of initial application of the approach in the teaching process, as well as of assessment of the strengths and weaknesses in applying the approach through a case study. Teaching trainee - multiplier, Martina Sulikova worked 25 minutes of the lesson with pupils of 8.A class (Kniezata Pribinu primary school in Nitra) on the theme of vocabulary - the human body. Video protocol is in the annex. Multiplier has defined the objectives within the presentation and practice stages: students will learn and practice new vocabulary of human body parts in French - using the equivalents in English (vocabulary they have already learned). From the temporal analysis of interactions multiplier - learner within the presentation and practice stages, we can conclude that during the learning process learners were actively involved. These video sequences indicate and confirm our research question: 01':00 - 01':17, 02':16 - 23':14. Level and content were consulted with the teacher of the class before creating the activity, and are consistent with the national and school curriculum.

From the indirect observation (video analysis) and content analysis, these FREPA descriptors were filled: "K 6.7.1 - Knows that languages may use different ways to indicate categories / relations (agreement / plural / possession), K 6.7.2 - Knows that the order in which elements making up a single word are placed may differ from one language to another, K 7.1.2 - Knows that it is normal to commit errors when one has not yet mastered a language, K 7.2 Knows that one can build on the (structural / discursive / pragmatic) similarities between languages in order to learn languages, K 7.4 - Knows that the perception one has of a language influences the learning of that language, Attitudes: A 2.3 - Sensitivity to linguistic / cultural similarities, A 4.2 Accepting the fact that another language / culture may function differently from one's language / culture, A 4.3 - Accepting the fact that another language / culture may include elements which differ from those of one's own language / culture, A 7.5 - Motivation to study / compare the functioning of different languages (structures, vocabulary, systems of writing) / cultures, A 17.4 - Having confidence in one's own abilities in language learning / in one's abilities to extend one's own linguistic competences, A 18.1.1 - Interest in the learning of language / languages of schooling (especially for allophonic learners), A 18.1.3 - A desire to learn other languages, A 18.3 - Being disposed to follow up autonomously, language learning started in a formal teaching context, S 1.2.1 - Can listen attentively / in a selective manner to productions in different languages, S 2.5 - Can identify languages 
on the basis of identification of linguistic forms, S 3.1.1 - Can establish similarity and difference between languages / cultures from observation / analysis / identification / recognition of some of their components, S 3.3.1 - Can perceive similarities and differences between graphic forms, S 7.3.2 - Can use knowledge and skills acquired in one language to learn another" [11]. The author and FREPA conceptor, Michel Candelier, added also following descriptors to the activity: "K 1.7 - Possesses knowledge of a linguistic nature about a particular language (the mother tongue / the language of schooling / foreign languages), K 6.3 Knows that categories used to describe the workings of a language (the mother tongue / the language of education) may not necessarily exist in others (number, gender, the article), $\mathrm{K}$ 6.4.1 - Knows that the number of elements which make up a category may vary from one language to another (masculine and feminine / masculine, feminine, neuter), A 9.2.1 - Considering the way languages and their different units (phonemes / words / sentences / texts) function as objects of analysis and reflection, A 15.2 . Considering every language / culture as "something" accessible (some aspects of which are already known)" [11].

In terms of the methodologists, who met during the joint observation, we can summarise that the integrated language approach, as well as other pluralistic approaches, should be applied adequately in order to develop the learner's plurilingual and pluricultural competence as well as general competences. This means working with languages to communicate - and not just for a mechanical comparison. Furthermore, in terms of age teachers are to customise tasks and cognitive goals. The analysis of the vocabulary forms and comparisons should not be applied, according to observers, in class where the case study was conducted. There should now be a discussion that could be maintained between FREPA conceptors and teachers and scientists in methodology of teaching foreign languages.

When teaching foreign languages with integrated language approach, we would need to have in class two or more teachers. Each of them would be approached by students with different communication needs and through different languages. Native speakers could have an essential role here. Though, such a requirement might be costly.
According to the teachers, the implementation of these approaches should follow the communicative objective specified in the situation, in a particular social activity. Teachers should prepare playful activities activating learner's spontaneity and his/ her ability to express ideas within a theme in multiple languages. Teachers - observers also declared that some modification is necessary for the state / school curriculum. Other stated that there is no need to include any changes in the contents of curricula, since the method chosen by the teacher depends mainly on his/ her motivation.

\section{Conclusion}

FREPA framework, in addition to communication specifically focuses on the comparison of linguistic aspects; especially in terms of otherness of languages and cultures. Plurilingual tasks can also be the restricted pre-communicative activities as well as communicative ones. During the collective observation, participants suggested several ideas for activities: pluricultural breakfast and conversation during breakfast, plurilingual commenting on the topic during discussion, role play in multiple languages.

Another condition or disadvantage is the lack of teaching materials or activities appropriate to their development and use.

When applying the integrated language approach, thus applying the teaching of the French language through the mother and first foreign language - English, teachers meet with a number of differences in language levels.

Common criteria for such foreign language teaching is richer time allocations, willingness of directors and teachers' qualifications, availability, or creation of activities and learners' interest to link knowledge with real communication needs and usage.

No pedagogical or methodological research in the domain of teaching techniques, of content for students of different ages and varying levels of interest for languages or are other pitfalls for the initial formal introduction of such approaches to foreign language lessons.

\section{References}

[1] WIDDOWSON, H. G.: Aspects of Language Teaching, Oxford : Oxford University Press, 1991.

[2] BYRAM, M.: Teaching and Assessing Intercultural Communicative Competence, Clevedon, Philadelphia : Multilingual Matters, 1997, Cadre europeen commun de reference pour les langues: Enseigner, Apprendre, Evaluer. Conseil de l'Europe - Didier, 2001.

[3] FAIRCLOUGH, N.: The appropriacy of 'appropriateness'. Critical Language Awareness, London and New York : Longman, 1992, 33-56.

[4] GONDOVA, D.: The Development of Speaking Skills in English Language Lessons. Communications - Scientific Letters of the University of Zilina, No. 1, 2012, 23-28. ISSN 1335-4205.

[5] ZARATE, G.: Enseigner une culture etrangere. Paris : Hachette, 1986. 
[6] BIROVA, J.: Les cas de l'EFLEIALE dans le contexte du systeme scolaire en Slovaquie, Le francais - deuxieme langue etrangere - La didactique integree des langues etrangeres. Katedra romanskych jazyku, Filozoficka fakulta : Plzen, Zapadoceska univerzita, 2008, 77-83.

[7] BIROVA, J., BUBAKOVA, J.: Multiculture, Plurilinguism and the Translation of the Chart of Plurilinguism, 2011, XLinguae: Trimestrial European Review. ISSN 1337-384, vol. 3, No 4, 2011, $51-58$.

[8] BURESOVA, B.: Russian Language as Another Foreign Language Taught on the Base of French (in Czech), Le français - deuxieme langue etrangere - La didactique integree des langues etrangeres, Katedra romanskych jazyku, Filozoficka fakulta, Zapadoceska univerzita : Plzen, 2008, 19-29.

[9] DEBYSER, F.: La linguistique contrastive et les interferences, Langue francaise, No. 8, 1970, 31-61.

[10] KRALOVA, Z.: Slovak-English Phonological Interference (in Slovak), Fakulta humanitnych vied : Zilinska univerzita, 2011. ISBN 978-80-554-0456-1.

[11] CANDELIER, M. et al.: Le CARAP, Un cadre de reference pour les approches plurielles des langues et des cultures, Graz : CELV, Conseil de 1'Europe. 2011. [online], [12.11.2011] Available at : 〈http://carap.ecml.at〉

[12] CANDELIER, M. et al.: Banque de materiaux didactiques (BMD)/Teaching materials bank, 132 cards. 2009. [online], [12.11.2011] Available at : 〈http://carap.ecml.at〉. 